\title{
Thermolysis of 1,3-dioxin-4-ones: Fast generation of kinetic data using in-line analysis under flow
}

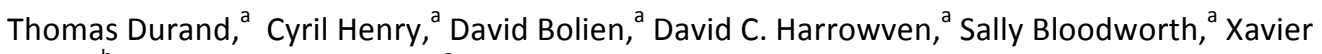 \\ Franck $^{\mathrm{b}}$ and Richard J. Whitby*a
}

\begin{abstract}
Rapid acquisition of kinetic data is demonstrated with a commercial meso-scale flow reactor, using a step-change in flow rate or 'push-out' from the flow line. For thermolysis of 1,3-dioxin-4-ones (1), we obtain excellent reproducibility in the activation energies measured from spectroscopic data collected by in-line UV or transmission FT-IR monitoring of the output during the transitional period between two flow rates $\left( \pm 3 \mathrm{~kJ} \mathrm{~mol}^{-1}, 0.7 \mathrm{kcal} \mathrm{mol}^{-1}\right)$. Analysis of multi-component UV and IR data is conducted using an orthogonal projection approach (multivariate curve resolution by alternating least squares) for complex spectra, or by calibration-less integration of non-overlapping peak absorbance. All analysis methods were validated using off-line ${ }^{1} \mathrm{H}$ NMR analysis, and kinetic parameters obtained using the method of a flow rate step-change were validated against conventional steady-state measurements in which time-series data were acquired across multiple experiments. Thermal transfer and dispersion effects are addressed. The experimental methods described herein are valuable for accelerated reaction study and in process development.
\end{abstract}

Received 00th January 20xx Accepted 00th January 20xx

DOI: $10.1039 / \times 0 \times x 00000 x$

www.rsc.org/ uninterrupted flow-rate adjustment is required however, and the ramped method is therefore not possible with most current commercial flow platforms.

The aim of our work was to demonstrate that widely available commercial flow reactors could be used for the rapid acquisition of kinetic data for reaction study and process development, enabling wider adoption of the stepped-rate method of 'push-out' from the flow line. The thermolysis of 1,3-dioxin-4-ones (1) was used to develop and illustrate the methods developed. We report the use of low-cost UV and transmission FTIR for in-line analysis, address the impact of dispersion (which could be reasonably neglected in the microflow reactor channels used in previous studies), and show that calibration-less multi-component analysis of the resulting spectra provides kinetic data with minimal operator intervention. The results are validated using both off-line ${ }^{1} \mathrm{H}$ NMR analysis and against known kinetic parameters.

\section{Results and Discussion}

Thermal decomposition of 1,3-dioxin-4-ones 1 via [4+2] retrocycloaddition, ${ }^{12}$ has been well-studied since trapping of intermediate acylketenes 3 with nucleophiles ${ }^{13}$ constitutes a synthetically useful acetoacetylation $\left(\mathrm{R}^{1}=\mathrm{Me}\right)$, for example in the preparation of $\beta$-ketoesters 4 when the trapping nucleophile is an alcohol (Scheme 1).

In particular, thermolysis of 2,2,6-trimethyl-4H-1,3-dioxin-4one $\left(1 \mathrm{a} \mathrm{R}^{1}=\mathrm{R}^{2}=\mathrm{Me}\right)$ in the presence of excess alcohol has been shown to be a first-order process ${ }^{14}$ in which the ratedetermining pre-equilibrium of $\mathbf{1 a}$ and the acyl ketene $\left(\mathbf{3 a}, \mathrm{R}^{1}=\right.$

\footnotetext{
${ }^{a .}$ Chemistry, Faculty of Natural and Environmental Sciences, University of Southampton, Southampton, SO17 1BJ, UK.

${ }^{b .}$ Normandie Université, COBRA, UMR 6014 \& FR 3038; Université de Rouen; INSA Rouen; CNRS, 1 rue Tesnière, 76821 Mont-Saint-Aignan Cedex, France. tElectronic Supplementary Information (ESI) available: See DOI: $10.1039 / \times 0 \times x 00000 x$
} 


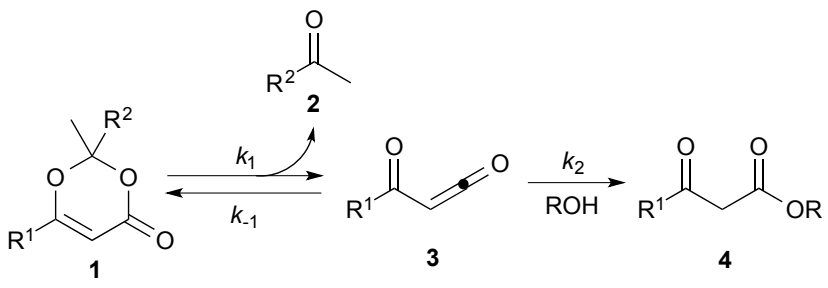

Scheme 1 Thermal cycloreversion of 1,3-dioxin-4-ones and acylketene trapping.

$\mathrm{Me})$ is followed by rapid trapping of 3a by an alcohol $\left(k_{2}[\mathrm{ROH}]\right.$ $>k_{-1}$ [acetone] $)^{13 \mathrm{a}, 15}$ such that the kinetic expression reduces as shown in Equation 1. Given the integrated rate law (Eq. 2), we first verified that the rate of reverse trapping of $\mathbf{3}$ with acetone $\left(k_{-1}\right)$ is not significant under flow conditions, by showing that the measured rate constant $k$ does not vary with alcohol stoichiometry. Classical steady-state measurement (using offline ${ }^{1} \mathrm{H}$ NMR analysis) gave a consistent first-order rate constant of $k=1.85 \times 10^{-3} \mathrm{sec}^{-1} \pm 1 \%$ for thermolysis of $1 \mathrm{a}$ in acetonitrile at $120^{\circ} \mathrm{C}$ in the presence of 1,2 or 4 equiv. EtOH. ${ }^{\dagger}$

$\frac{d[\mathbf{1 a}]}{d t}=\frac{k_{1} k_{2}[\mathbf{1 a}][\mathrm{ROH}]}{k_{-1}[\text { acetone }]+k_{2}[\mathrm{ROH}]}$

$\frac{d[\mathbf{1} \mathbf{a}]}{d t}=k_{1}[\mathbf{1 a}]$ if $k_{2}[\mathrm{ROH}] \gg k_{-1}$ [acetone $]$

$\ln [\mathbf{1} \mathbf{a}]_{\mathrm{t}}=-k_{1} t_{r}+\ln [\mathbf{1} \mathbf{a}]_{0}$

We next sought to apply the push-out method for the study of reaction kinetics under mesoscale flow conditions, using the thermal cycloreversion of 1a in the presence of 4 equiv. EtOH (premixed) as our proving ground. An excess of the alcohol trap for intermediate acylketene $3 \mathbf{a}\left(\mathrm{R}^{1}=\mathrm{Me}\right)$ was used in order to suppress possible side reactions of $\mathbf{3 a}$; either condensation with acetone (2a, $\mathrm{R}^{2}=\mathrm{Me}$, enol form) to give 2,6-dimethyl- $4 H$ pyran-4-one, ${ }^{14,16}$ or [4+2] self-cycloaddition to give dehydro acetic acid. ${ }^{13 a}$

Our experiments under flow conditions were conducted using a Vapourtec R series (R2+/R4) system with $10 \mathrm{~mL}$ capacity stainless steel reactor of $1 \mathrm{~mm}$ internal diameter heated by an external oil bath (see below), flow-rate switching within a range of $0.02-10 \mathrm{~mL} \mathrm{~min}^{-1}$, and in-line IR or UV spectroscopic data collection. An alpha transmission FT-IR from Bruker was integrated into the flow system using a Harrick DLC2 ${ }^{\mathrm{TM}}$ demountable liquid flow cell with sodium chloride windows and IR spectra were recorded with a 3.75 second interval. Inline UV measurements were recorded on an Ocean Optics DH2000-BAL spectrometer integrated into the flow with a type

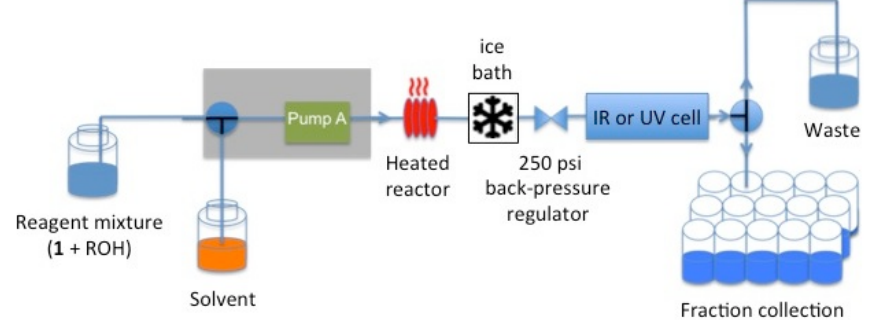

Figure 1 Cartoon of flow set-up utilising a single channel (Pump A) of the Vapourtec $R$ series platform and bottle-feed configuration, $10 \mathrm{~mL}$ stainless steel reactor submerged in a precision oil bath, ice bath cooling of the reactor efflux, 250 psi back-pressure regulation and in-line IR or UV data acquisition.

583-F Starna ${ }^{\circledR}$ fluorimeter flow cell $(1 \mathrm{~mm}$ path length, 0.011 $\mathrm{mL}$ volume), enabling collection of UV spectra with a 1.2 second interval. The ability to switch either the described inline UV or IR analysis into the reactor output flow line means that spectroscopic analysis across a reagent concentration range of $0.001-0.3 \mathrm{M}$ is readily achieved. The system was further equipped with an automated sample collector for off-line product analysis (Figure 1).

The method of kinetic data acquisition is described in Figure 2; a typical concentration profile for [1a] obtained, in this example, through UV monitoring of the flow output is depicted in Figure 2(a). At each given temperature, once the system has reached steady-state at low flow-rate $\left(\mathrm{F}_{1}=\right.$ typically $1 \mathrm{~mL} \mathrm{~min}$


is applied, resulting in a second steady-state of correspondingly lower 1,3-dioxin-4-one reaction. The transitional period between steady-states gives spectroscopic information across a gradient of residence times within the reactor. The reaction time $\left(t_{r}\right)$ of individual data points is determined from the experimental time $(\tau)$ and inflection points $\tau_{1}$ and $\tau_{0}$ (Eq. 3$)^{10}$ with further correction for thermal expansion of solvent. ${ }^{17}$

$t_{r}=\frac{\mathrm{F}_{2}-\mathrm{F}_{1}}{\mathrm{~F}_{1}} \tau+\frac{\mathrm{F}_{2}}{\mathrm{~F}_{1}} \tau_{1}-\tau_{0}$

Chemometric methods for (calibration-less) spectral deconvolution of multivariate spectra are well developed for quantitative analysis in process monitoring ${ }^{18}$ and, in order to reconstruct reactant concentration, multivariate curve resolution of spectra by alternating least squares method (MCR-ALS) ${ }^{19}$ was performed using the orthogonal projection approach $(\mathrm{OPA}){ }^{20}$ In all cases, MCR-ALS resolved two spectral components consistent with clean thermolysis and trapping of $\mathbf{1} \mathbf{a}^{\dagger}{ }^{\dagger}$ with the component whose concentration profile correlates with that expected for 1a displaying a UV spectrum consistent with the 1,3-dioxin-4-one ( $\lambda_{\max } 245.9 \mathrm{~nm}$ ). Representative kinetic data is shown in Figure 2(c) and an Arrhenius plot of the first-order rate constants against the reciprocal of temperature 


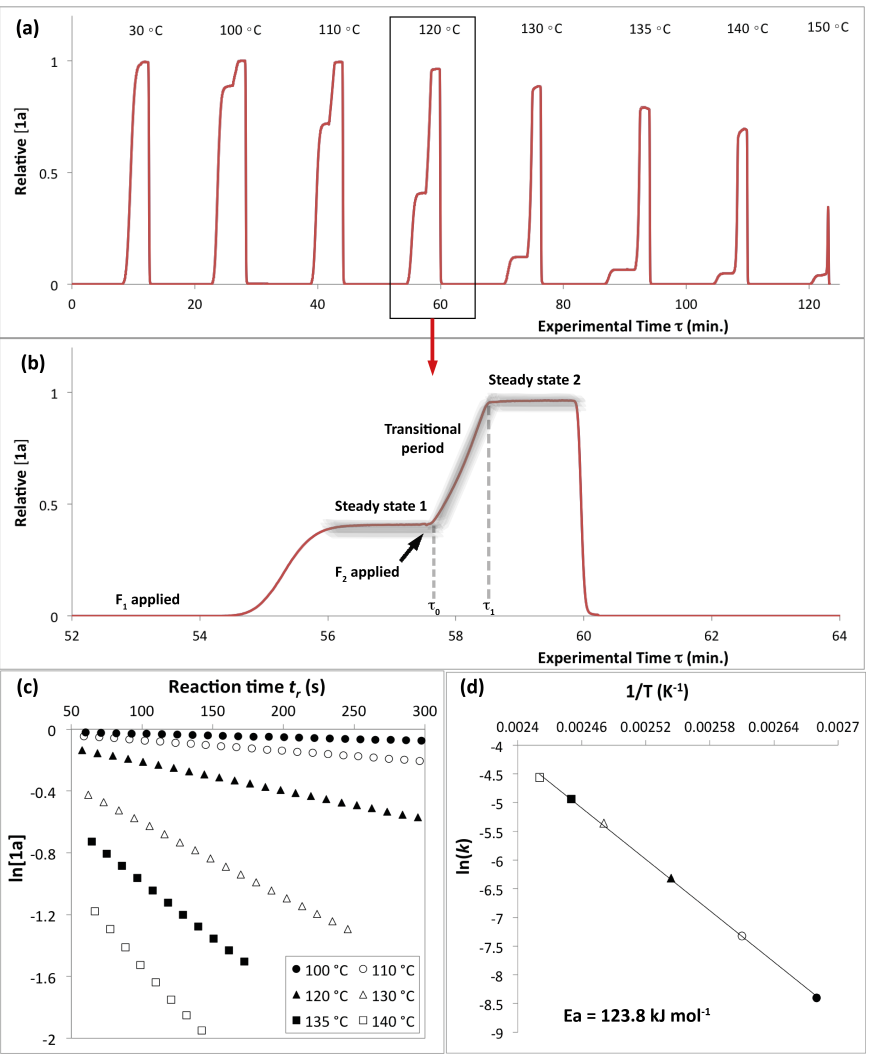

Figure 2 Representative data derived from a push-out experiment (this example is Entry 1 of Table 1, vide infra). (a) Concentration profile of 2,2,6-trimethyl-4H-1,3dioxin-4-one (1a) derived from OPA resolution of UV spectra obtained in-situ from flow thermolysis in the presence of EtOH (4 equiv.) under stepped flow-rate (push-out) conditions at each of the temperatures indicated. (b) Detailed push-out profile for flow thermolysis of $1 \mathrm{a}$ at $120^{\circ} \mathrm{C}$. (c) First-order kinetics and (d) Arrhenius plots derived from relative [1a] data.

[Fig. 2(d)] enables calculation of the activation energy of 1,3dioxin-4-one thermolysis. Commercially available flow systems are generally designed to work on the meso-scale with typical flow rates of between 0.1 and $10 \mathrm{~mL} \mathrm{~min}^{-1}$, and tube diameters of $\sim 1 \mathrm{~mm}$. Under these conditions flow will be laminar (Reynolds number $<2000$ ) and significant Taylor dispersion ${ }^{21}$ is to be expected. The effect of dispersion is that a sample plug exiting the reactor tubing at a particular time contains material having experienced a range of residence times. The form of the dispersion will have the same residence time distribution (RTD) as that measured for a very short plug of material introduced to and traversing the tube, upon its exit from the tube.

We needed to determine the likely maximum error which dispersion might cause in kinetic studies under push-out conditions. The situation is complicated as the RTD of the material just leaving the reactor column when the step-change in flow rate is applied will be different to the RTD of that which leaves the reactor at the end of the push-out period, as the flow rates while passing through the column are different. Figure 3 shows the observed dispersion of a $10 \mu \mathrm{L}$ sample of a solution of benzophenone in $\mathrm{MeCN}$, passed through a coiled tubular column of $10 \mathrm{~mL}$ capacity and $1 \mathrm{~mm}$ internal diameter at flow rates of 10,1 and $0.2 \mathrm{~mL} \mathrm{~min}^{-1}$ at $30^{\circ} \mathrm{C}$. The dispersion

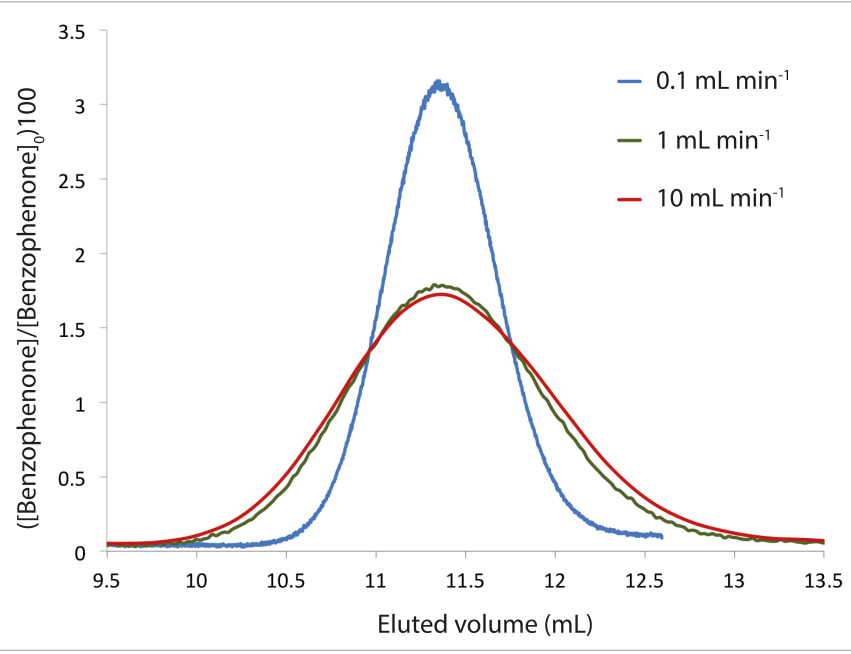

Figure 3 Dispersion of a $10 \mu \mathrm{L}$ sample plug of benzophenone in $\mathrm{MeCN}$ ([Benzophenone $]_{0}=1.015 \times 10^{-2} \mathrm{M}$ ) through coiled stainless steel tubing of $1 \mathrm{~mm}$ internal diameter and $10 \mathrm{~mL}$ capacity at $30{ }^{\circ} \mathrm{C}$ and the flow rates indicated. Concentrations were obtained by UV absorbance.

is shown with respect to volume passing the observation point, rather than time. Dispersion is considerably reduced at higher temperatures and slower flow rates (see supporting information ${ }^{\dagger}$ ) such that the $10 \mathrm{~mL} \min ^{-1}$ case in Figure 3 represents a worst case for our studies. It can be seen that the dispersion is significant with respect to the total passage of volume/time, for example the $90 \%$ peak width at $10 \mathrm{~mL} \mathrm{~min}^{-1}$ is around $0.2 \mathrm{~min}$. $c f$. a total spectroscopic sampling time of 1 min. Fortunately the dispersion at higher flow rates is much less than would be predicted from simple Taylor dispersion in a linear capillary due to transverse mixing induced by Dean circulation $^{22,23}$ as a result of the curved nature of the reactor coil. For the two flow rates used in most of the push-out experiments described below ( 10 and $\left.1 \mathrm{~mL} \mathrm{~min}^{-1}\right)$ dispersion is very similar.

Provided that the RTD is symmetric, the average reaction time will be the same as the observed reaction time (i.e. that calculated from the residence time according to Mozharov et al. ${ }^{10}$ ). For dispersion profiles obtained at flow rates between 0.1 and $10 \mathrm{~mL} \mathrm{~min}{ }^{-1}$, at both $30{ }^{\circ} \mathrm{C}$ and $120{ }^{\circ} \mathrm{C}$, the difference between the weighted average retention time, and the retention time of the peak top was insignificant. The average conversion will thus be very close to that expected at this time point unless the conversion $v s$. time is highly non linear. Using the dispersion profile from the 'worst case' scenario $\left(10 \mathrm{~mL} \mathrm{~min}^{-1}\right.$, $30{ }^{\circ} \mathrm{C}$ ) we simulated the effect of dispersion upon calculated kinetic parameters of $1^{\text {st }}$ and $2^{\text {nd }}$ order reactions under push-out conditions, choosing theoretical rate constants corresponding to $80 \%$ conversion at the longest reaction time. The effect of dispersion was found to be negligible in each case. ${ }^{\dagger}$ An effect is only seen at either end of the push-out period where spectroscopic data under each of the two steady-state flow rate conditions (e.g. $1 \mathrm{~mL} \mathrm{~min}$-1 and $10 \mathrm{~mL} \mathrm{~min}^{-1}$ ) is averaged-in; apparent as a slight deviation at each end of a plot of [reagent] $v s$. experimental time (Figure 4) and also by the very slight 


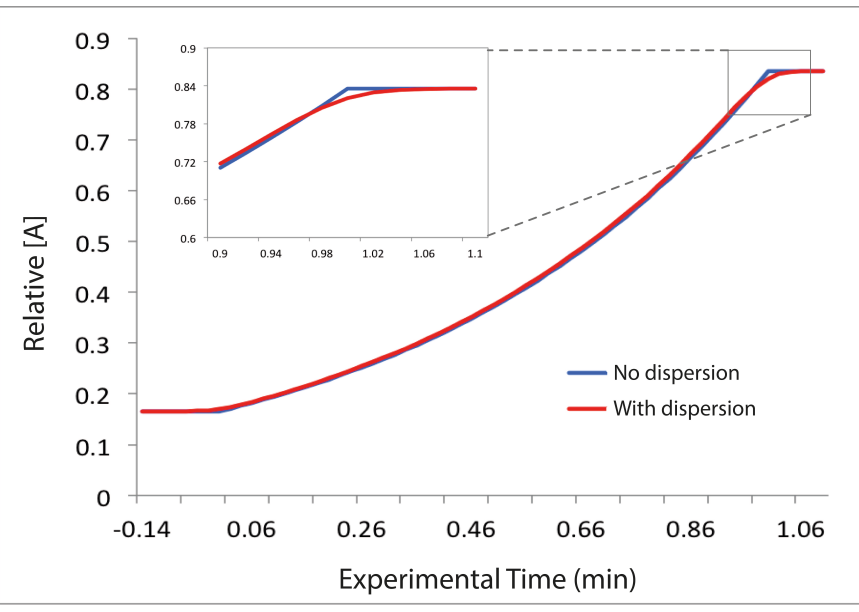

Figure 4 Simulated reagent concentration profiles for a 1st order reaction $\mathrm{A} \rightarrow \mathrm{P}$ under push-out conditions of stepped flow-rate from $1 \mathrm{ml} \mathrm{min}^{-1}$ to $10 \mathrm{~mL} \mathrm{~min}^{-1}$ with flow rate switching at experimental time $t=0$. Since flow rate increases across the push-out period, residence (reaction) time decreases with increasing experimental time. The indicated profile 'with dispersion' (red line) was generated by redistribution of each data point in the profile with 'no dispersion' (blue line) according to a dispersion profile of benzophenone in $\mathrm{MeCN}$ obtained experimentally at $30^{\circ} \mathrm{C}$ and flow rate $=10 \mathrm{~mL} \mathrm{~min}$ ${ }^{1}$ in reactor tubing of $10 \mathrm{~mL}$ capacity and $1 \mathrm{~mm}$ internal diameter.

Table 1 Rate constants and activation energies for thermolysis of 2,2,6-trimethyl-4H-1,3-dioxin-4-one (1a) in the presence of an alcohol ROH (4 equiv.) in acetonitrile.

\begin{tabular}{|c|c|c|c|c|c|c|c|c|c|c|c|c|c|c|c|}
\hline \multirow{3}{*}{ Entry ${ }^{a}$} & \multirow{3}{*}{$\begin{array}{l}\text { Kinetic } \\
\text { Method }^{b}\end{array}$} & \multirow{3}{*}{$\begin{array}{l}\text { Analysis } \\
\text { Method }\end{array}$} & \multirow{3}{*}{$\begin{array}{l}\text { Process } \\
\text { Method }^{c}\end{array}$} & $\mathrm{~F}_{1}$ & $F_{2}$ & \multirow{3}{*}{$\mathrm{ROH}$} & \multicolumn{8}{|c|}{$k \times 10^{-3}\left(\mathrm{~s}^{-1}\right)$} & \multirow{3}{*}{$\begin{array}{c}\mathrm{E}_{\mathrm{a}} \\
\mathrm{kJ} \mathrm{mol}^{-1}\end{array}$} \\
\hline & & & & \multirow{2}{*}{\multicolumn{2}{|c|}{$\mathrm{mL} \mathrm{min}^{-1}$}} & & 100 & 110 & 115 & 120 & 125 & 130 & 135 & 140 & \\
\hline & & & & & & & \multicolumn{8}{|c|}{ 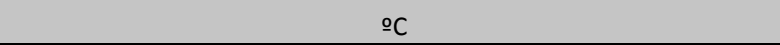 } & \\
\hline 1 & Push-out & $\begin{array}{l}\text { In-line } \\
\text { UV }\end{array}$ & OPA & 1 & 10 & EtOH & 0.23 & 0.66 & - & 1.81 & - & 4.70 & 7.17 & 10.44 & 123.8 \\
\hline 2 & Push-out & $\begin{array}{l}\text { In-line } \\
\text { UV }\end{array}$ & Peak abs. & 1 & 10 & EtOH & 0.23 & 0.65 & - & 1.82 & - & 4.74 & 7.07 & 10.81 & 123.8 \\
\hline 3 & $\begin{array}{l}\text { Steady- } \\
\text { state }\end{array}$ & $\begin{array}{l}\text { In-line } \\
\text { UV }\end{array}$ & OPA & - & - & EtOH & 0.24 & 0.68 & - & 1.89 & - & 4.92 & - & - & 126.7 \\
\hline 4 & Push-out & In-line IR & OPA & 1 & 10 & EtOH & 0.27 & 0.71 & 1.17 & 1.92 & 3.16 & 5.06 & 7.97 & 11.58 & 123.5 \\
\hline 5 & Push-out & In-line IR & Peak abs. & 1 & 10 & EtOH & 0.25 & 0.66 & 1.09 & 1.80 & 3.04 & 4.78 & 7.56 & 11.36 & 125.0 \\
\hline 6 & $\begin{array}{l}\text { Steady- } \\
\text { state }\end{array}$ & In-line IR & OPA & - & - & EtOH & - & 0.72 & - & 1.83 & 3.15 & 5.11 & - & 11.96 & 124.4 \\
\hline 7 & $\begin{array}{l}\text { Reverse } \\
\text { push-out }\end{array}$ & $\begin{array}{l}\text { In-line } \\
\text { UV }\end{array}$ & OPA & 10 & 1 & EtOH & - & 0.62 & 0.96 & 1.66 & 2.80 & 4.47 & - & - & 128.7 \\
\hline 8 & Push-out & In-line IR & OPA & 1 & 2 & EtOH & - & 0.66 & 1.26 & 1.96 & 2.93 & 4.80 & - & - & 123.9 \\
\hline 9 & Push-out & $\begin{array}{l}\text { In-line } \\
\text { UV }\end{array}$ & OPA & 1 & 2 & EtOH & - & - & 1.03 & 1.74 & 2.89 & 4.82 & - & 11.30 & 128.2 \\
\hline 10 & $\begin{array}{l}\text { Steady- } \\
\text { state }\end{array}$ & $\begin{array}{c}\text { Off-line } \\
\text { NMR }\end{array}$ & - & - & - & EtOH & - & 0.65 & - & 1.89 & 2.97 & 5.13 & - & 12.52 & 129.9 \\
\hline 11 & $\begin{array}{l}\text { Steady- } \\
\text { state }\end{array}$ & $\begin{array}{c}\text { Off-line } \\
\text { NMR }\end{array}$ & - & - & - & $\mathrm{BnOH}$ & - & 0.67 & - & 1.79 & 2.85 & 4.88 & 7.74 & - & 127.9 \\
\hline
\end{tabular}

${ }^{a}$ For entries $3,6,7,10$ and 11 rate constants were determined from an individual flow experiment; for 'paired' entries $1+2,4+5$ and $8+9$ IR and UV data were collected from the same flow output. 'Push-out' refers to the method of stepped flow-rate from $F_{1}$ to $F_{2}$ with time-series data acquisition across the transitional period within a single experiment, 'steady-state' refers to acquisition of time-series data across multiple experiments (typically five) in which a range of flow rates (each being constant within a given experiment) corresponds to a range of reaction times calculated from the reactor residence time upon correction for thermal expansion of solvent. ' 'OPA' refers to orthogonal projection approach MCR-ALS analysis, 'Peak abs.' refers to calibration-less calculation of [1a] by integration of nonoverlapping peaks in the UV or IR spectrum with respect to $0 \%$ conversion. Off-line analysis of ${ }^{1} \mathrm{H}$ NMR spectra was conducted manually. ${ }^{\dagger}$ 
are given in supporting information. ${ }^{\dagger}$

The results of kinetic studies upon thermolysis of 2,2,6trimethyl-4H-1,3-dioxin-4-one (1a) in the presence of 4 equiv. of trapping alcohol in acetonitrile are given in Table 1. Good consistency was obtained between the push-out method and conventional steady-state measurement of kinetic parameters in which time-series data was acquired across multiple experiments (entry 1 vs. 3 and 4 vs. 6). In addition, corroboration of results obtained through calibration-less processing using OPA (MCR-ALS) and using peak absorbance was good (entries 1 vs. 2 and 4 vs. 5). Relative integration of both IR and UV peaks with respect to a $[\mathbf{1 a}]_{0}$ value determined by conducting flow throughput at $25^{\circ} \mathrm{C}$ was possible since nonoverlapping spectroscopic data were obtained in each case. There was good consistency between the results obtained using UV and IR monitoring (entries 1-3 vs. 4-6), and both were in agreement with the results obtained from manual calculation of $[\mathbf{1 a}] /[\mathbf{1 a}]_{0}$ using off-line ${ }^{1} \mathrm{H}$ NMR analysis (entry 10). The later was repeated using $\mathrm{BnOH}$ (entry 11) instead of $\mathrm{EtOH}$ as the trap due to concerns about the volatility of the products, with similar results. Detailed data characterisation is given in supporting information although it is interesting to specifically note that, in accord with the clean resolution of mixed component UV spectra mentioned above, no evidence of competing condensation of acylketene intermediate 3a with acetone (2a), or of [4+2] self-cycloaddition of 3a, was apparent in the NMR spectra.

Excellent reproducibility in the calculated activation energy of cycloreversion of $1 \mathrm{a}$ was achieved overall, $E_{\mathrm{a}}=126.7 \pm 3.2 \mathrm{~kJ}$ $\mathrm{mol}^{-1}\left(c f . E_{\mathrm{a}}=130.1 \pm 4.6 \mathrm{~kJ} \mathrm{~mol}^{-1}\right.$ reported by Witzeman and Clemens ${ }^{14}$ for thermolysis of $\mathbf{1 a}$ in xylene), independent of the trapping nucleophile (compare entries 10 and 11) as expected. Consistent rate constants were determined regardless of the analysis or process method used and no loss of reproducibility in the push-out experiments was observed across the temperature range studied, suggesting that heat transfer from the heated oil bath to the reactor coil is efficient across this range, such that there is not significant cooling of the initial section of the reactor by entering solvent, even at the high flow rate $\mathrm{F}_{2}$.

The short data acquisition time associated with the method of a step-change in flow rate has attracted the criticism that noninstantaneous flow rate adjustment limits the number of data points which can be acquired. ${ }^{11}$ The use of a ramped change in flow rate to address this issue is not available using most commercial flow systems. Fortunately a simple solution is to be found in a 'reverse push out' method where a step-change from high to low flow rate effects access to time-series data within an (extended) transitional period of increasing reaction conversion (Figure 5). Mozharov et al. ${ }^{10}$ have shown that the error associated with non-instantaneous flow-rate adjustment, can be minimised by reducing $\Delta \tau\left(\mathrm{F}_{2} / \mathrm{F}_{1}\right)$, where $\Delta \tau$ is the interval between consecutive spectroscopic measurements taken at the reactor output. Under our reverse push-out conditions of flow


0.12 (UV) or 0.375 (IR). In comparison, 'standard' push-out

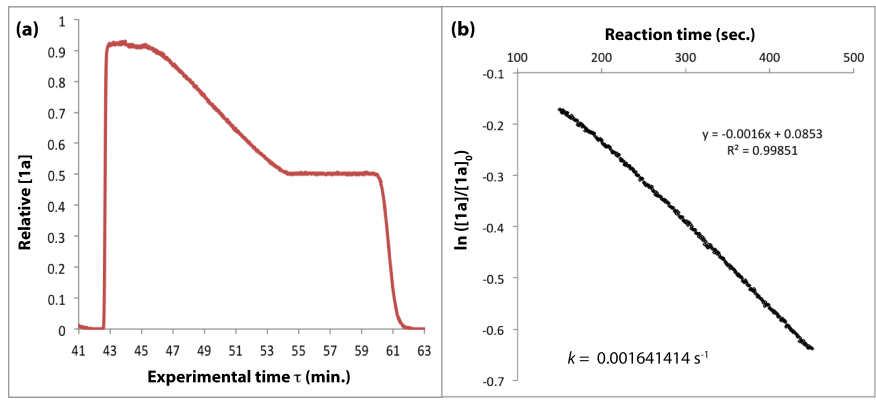

Figure 5 (a) Reagent (1a) concentration profile and (b) kinetic plot of 314 datapoints; obtained from OPA resolution of UV spectra recorded in-situ for flow thermolysis of 2,2,6-trimethyl- $4 \mathrm{H}$-1,3-dioxin-4-one in the presence of $\mathrm{EtOH}$ (4 equiv.) under reverse push-out conditions $\left(F_{1}=10 \mathrm{~mL} \mathrm{~min}^{-1}\right.$ and $\left.F_{2}=1 \mathrm{~mL} \mathrm{~min}^{-1}\right)$ at $120^{\circ} \mathrm{C}$.

(i.e. flow rate switching of $1 \mathrm{ml} \mathrm{min}-1 \rightarrow 10 \mathrm{~mL} \mathrm{~min}^{-1}$ ) involves a transitional period of ca. 50 sec. and correspondingly $\Delta \tau\left(F_{2} / F_{1}\right)=12(\mathrm{UV})$ or 37.5 (IR). Table 1 entry 7 demonstrates that the reverse push-out method gives the same result as the normal push-out method. Whilst greater consumption of reagent is required for equilibration of the flow platform to steady state at a high flow rate, the technique is useful when sampling rate is a limitation. An alternative approach is to use a smaller stepped rate-change of $1 \mathrm{~mL} \mathrm{m^{-1 } \rightarrow 2 \mathrm { mL } \mathrm { min }}{ }^{-1}$ equating to $\Delta \tau\left(F_{2} / F_{1}\right)=2.4$ (UV) or 7.5 (IR). Remarkably good kinetic results are obtained (Table 1, entries 8 and 9), but following a reaction through such a small conversion range is inadvisable since, for example, the linearity of the kinetic plots can no longer be taken to confirm $1^{\text {st }}$ order behaviour.

In order to exploit the fast generation of kinetic data for reaction study, we next sought to conduct a short exploration of substituent effects upon 1,3-dioxin-4-one thermolysis. A series of 1,3-dioxin-4-ones $\mathbf{1 b}$-i, variably substituted $\left(R^{1} \neq R^{2}=M e\right.$, aryl) at the 2- and 6-positions, were prepared from condensation between a $\beta$-substituted- $\beta$-keto tert-butyl ester ${ }^{24} \mathbf{5}$ and ketone 6 under acidic conditions (Scheme 2). ${ }^{25}$ Activation energies for thermal cycloreversion of $\mathbf{1 b}-\mathbf{i}$ were then determined, in the presence of 4 equiv. EtOH in acetonitrile, according to the methods already described (Table 2).

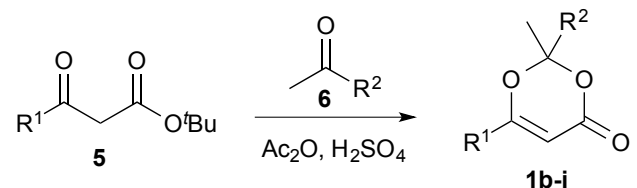

\begin{tabular}{|r|c|c|}
\cline { 2 - 3 } \multicolumn{1}{c|}{} & $\mathbf{R}^{\mathbf{1}}$ & $\mathbf{R}^{\mathbf{2}}$ \\
\hline $\mathbf{1 b}$ & $\mathrm{Me}$ & $\mathrm{Ph}$ \\
$\mathbf{1 c}$ & $\mathrm{Me}$ & $p-\mathrm{MeOC}_{6} \mathrm{H}_{4}$ \\
$\mathbf{1 d}$ & $\mathrm{Me}$ & $p-\mathrm{BrC}_{6} \mathrm{H}_{4}$ \\
$\mathbf{1 e}$ & $\mathrm{Ph}$ & $\mathrm{Me}$ \\
$\mathbf{1 f}$ & $p$ - $\mathrm{MeOC}_{6} \mathrm{H}_{4}$ & $\mathrm{Me}$ \\
$\mathbf{1 g}$ & $p$ - $\mathrm{NO}_{2} \mathrm{C}_{6} \mathrm{H}_{4}$ & $\mathrm{Me}$ \\
$\mathbf{1 h}$ & 2 -furyl & $\mathrm{Me}$ \\
$\mathbf{1 i}$ & 2-naphthyl & $\mathrm{Me}$ \\
\hline
\end{tabular}

Scheme 2 Dioxinone synthesis. 
For thermal cycloreversion of $\mathbf{1 b}$, kinetic parameters obtained using the push-out method were again substantiated by close correlation with those obtained from steady-state experiments (compare entries 1 and 3). For both $1 \mathbf{b}$ (entries $1-4$ ) and 1c (entries $5-6$ ), different methods of spectroscopic analysis and/or data processing were also found to give consistent values of activation energy. Retro-cycloaddition of $\mathbf{1 d - i}$ was therefore conducted solely using the push-out method with inline UV analysis and OPA processing (entries 7 and $10-14$; further scrutiny of the thermolysis of $1 \mathbf{d}$ reported in entries 8 9 was conducted subsequently vide infra). First-order rate constants for decomposition of 1a-i gave excellent linear Arrhenius plots (Figure 6) allowing activation energies to be estimated. In general, the differences between activation energies obtained for $\mathbf{1 a - i}$ are too small for detailed interpretation. Nonetheless, the substantial decrease in activation energy observed when $\mathrm{R}^{2}=p-\mathrm{MeOC}_{6} \mathrm{H}_{4}$, together with a significant increase when $\mathrm{R}^{1}=p-\mathrm{MeOC}_{6} \mathrm{H}_{4}$, suggests a transition state in which the $\mathrm{C} 2-\mathrm{O} 1$ bond is substantially broken
(Figure 7). Moreover, the observation that, in several cases, similar rates are associated with different activation energies and vice versa, indicates that entropic effects are important. These are likely to be due to the reorganisation of solvent molecules around the sites of developing charge.

The use of OPA or related curve analysis methods is a substantial advance over following the intensity of single peaks in spectroscopic data, particularly in the case of UV monitoring where compounds are characterised by a few very broad, featureless peaks. In the case of $\mathbf{1 b}, \mathbf{c}$ and $\mathbf{d}$ we were concerned that the strength of the UV absorptions of the aryl ketone 2 (Scheme 1) eliminated in the reaction, and their very substantial overlap with the absorption of the reagent 1,3-dioxin-4-ones, may cause difficulty. For these examples we also acquired the kinetic information using IR monitoring, with close results confirming the ability of the OPA method to distinguish between similar chromophores. For $\mathbf{1 b}$ we also confirmed the results using steady-state experiments with both UV and offline NMR monitoring.

Table 2 Rate constants and activation energies for thermolysis of substituted 1,3-dioxin-4-ones (1)-i) in the presence of EtOH (4 equiv.) in acetonitrile.

\begin{tabular}{|c|c|c|c|c|c|c|c|c|c|c|c|c|c|c|}
\hline \multirow{3}{*}{ Entry ${ }^{a}$} & \multirow{3}{*}{$\begin{array}{l}\text { 1,3-dioxin-4- } \\
\text { one }\end{array}$} & \multirow{3}{*}{$\begin{array}{l}\text { Kinetic } \\
\text { Method }^{b}\end{array}$} & \multirow{3}{*}{$\begin{array}{l}\text { Analysis } \\
\text { Method }\end{array}$} & \multicolumn{10}{|c|}{$k \times 10^{-3}\left(\mathrm{~s}^{-1}\right)$} & \multirow{3}{*}{$\begin{array}{c}\mathrm{E}_{\mathrm{a}} \\
\mathrm{kJ} \mathrm{mol}^{-1}\end{array}$} \\
\hline & & & & 85 & 90 & 95 & 100 & 105 & 110 & 115 & 120 & 125 & 130 & \\
\hline & & & & \multicolumn{10}{|c|}{$\stackrel{\circ}{ } \mathrm{C}$} & \\
\hline 1 & $1 \mathrm{~b}$ & Push-out & $\begin{array}{l}\text { In-line } \\
\text { UV }\end{array}$ & - & 0.24 & 0.45 & 0.76 & 1.32 & 2.19 & 3.54 & 5.75 & - & - & 125.2 \\
\hline 2 & $1 \mathrm{~b}$ & Push-out & In-line IR & - & - & 0.48 & 0.74 & 1.27 & 2.08 & 3.55 & 5.84 & - & - & 121.4 \\
\hline 3 & $1 \mathrm{~b}$ & $\begin{array}{l}\text { Steady- } \\
\text { state }\end{array}$ & $\begin{array}{c}\text { In-line } \\
\text { UV }\end{array}$ & - & - & - & 0.80 & 1.31 & 2.30 & 3.70 & 6.16 & - & - & 124.9 \\
\hline $4^{c}$ & $1 \mathrm{~b}$ & $\begin{array}{l}\text { Steady- } \\
\text { state }\end{array}$ & $\begin{array}{l}\text { Off-line } \\
\text { NMR }\end{array}$ & - & - & - & 0.79 & 1.24 & 2.33 & 3.29 & 6.26 & - & - & 124.6 \\
\hline 5 & $1 c$ & Push-out & $\begin{array}{l}\text { In-line } \\
\text { UV }\end{array}$ & 1.66 & 2.78 & 4.71 & 7.55 & 11.49 & 17.18 & - & - & - & - & 107.2 \\
\hline 6 & $1 \mathrm{c}$ & Push-out & In-line IR & - & 2.65 & 4.52 & 7.15 & 11.11 & - & - & - & - & - & 108.6 \\
\hline 7 & $1 d$ & Push-out & $\begin{array}{l}\text { In-line } \\
\text { UV }\end{array}$ & - & - & - & 0.59 & 0.94 & 1.59 & 2.68 & 4.54 & 7.80 & - & 128.3 \\
\hline 8 & 1d & Push-out & In-line IR & - & - & - & 0.56 & 1.06 & 1.82 & 2.91 & - & 7.47 & - & 126.6 \\
\hline 9 & 1d & Push-out & $\begin{array}{c}\text { Off-line } \\
\text { NMR }\end{array}$ & - & - & - & 0.55 & 0.95 & 1.62 & 2.60 & - & 7.42 & - & 128.0 \\
\hline 10 & $1 e$ & Push-out & $\begin{array}{l}\text { In-line } \\
\text { UV }\end{array}$ & - & - & - & - & 0.32 & 0.55 & 0.93 & 1.56 & 2.58 & 4.04 & 128.6 \\
\hline 11 & $1 f$ & Push-out & $\begin{array}{l}\text { In-line } \\
\text { UV }\end{array}$ & - & - & - & - & - & 0.44 & 0.76 & 1.30 & - & 3.62 & 136.0 \\
\hline 12 & $1 \mathrm{~g}$ & Push-out & $\begin{array}{l}\text { In-line } \\
\text { UV }\end{array}$ & - & - & - & 0.57 & 0.91 & 1.53 & 2.47 & 4.15 & - & - & 120.9 \\
\hline 13 & $1 \mathrm{~h}$ & Push-out & $\begin{array}{l}\text { In-line } \\
\text { UV }\end{array}$ & - & 0.37 & 0.61 & 1.05 & 1.72 & 2.99 & 4.95 & - & - & - & 122.3 \\
\hline 14 & $1 \mathrm{i}$ & Push-out & $\begin{array}{l}\text { In-line } \\
\text { UV }\end{array}$ & - & - & - & 0.21 & 0.34 & 0.59 & 0.96 & 1.60 & - & 3.98 & 124.0 \\
\hline
\end{tabular}

${ }^{a}$ Each entry quotes rate constants determined from an individual flow experiment. ' 'Push-out' refers to the method of stepped flow-rate from $F_{1}=1 \mathrm{~mL}$ min ${ }^{-1}$ to $F_{2}=$ $10 \mathrm{~mL} \mathrm{~min}$-1 with time-series data acquisition across the transitional period within a single experiment. 'Steady-state' refers to acquisition of time-series data across multiple experiments (typically five) in which a range of flow rates (each being constant within a given experiment) corresponds to a range of reaction times calculated from the reactor residence time upon correction for thermal expansion of solvent. All data was processed using orthogonal projection approach MCR-ALS analysis with the exception of analysis of ${ }^{1} \mathrm{H}$ NMR spectra (entries 4 and 9) which was conducted manually. ${ }^{+c} \mathrm{BnOH}$ (4 equiv.) was used as the alcohol trap. 

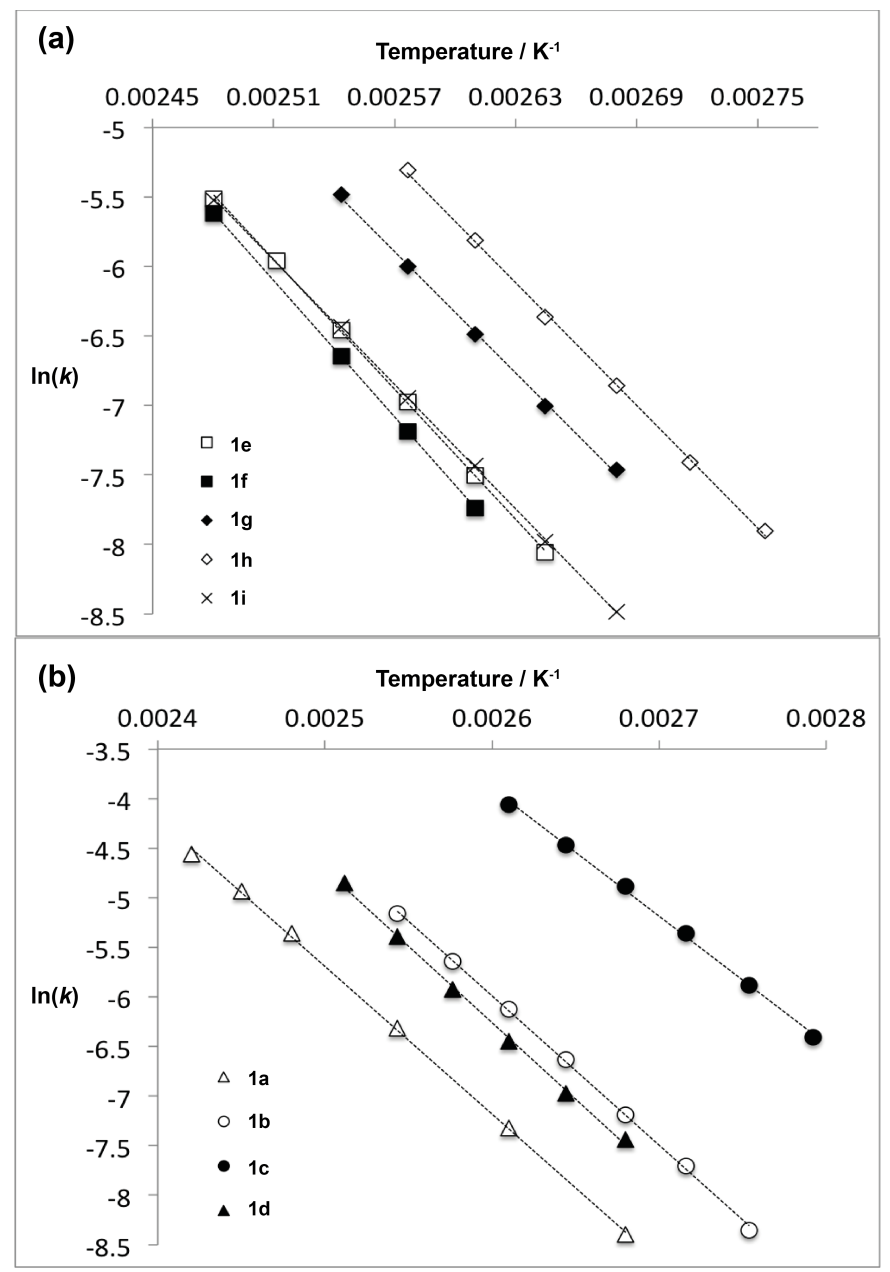

Figure 6 Arrhenius plots for thermal decomposition of (a) 1,3-dioxin-4-ones 1e-i with different 6-position substituent $R^{1}$ and (b) 1,3-dioxin-4-ones 1a-d with different 2position substituent $\mathrm{R}^{2}$.
For compound 1d we also introduced the use of NMR to monitor a push-out experiment by using a fraction collector to split the output into 20 samples which were then analysed by off-line ${ }^{1} \mathrm{H}$ NMR. The resulting $E_{\mathrm{a}}$ (Table 2 entry 9) was in excellent agreement with that obtained using in-line UV and IR analysis ( $c f$. entries 7 and 8 ).

\section{Conclusions}

The 'push-out' technique using a stepped flow rate in a continuous flow reactor has been developed using a widely available commercial flow reactor, to rapidly obtain kinetic data of suitable quality for application in process development chemistry.

Integration of in-line UV and transmission FT-IR provides a versatile breadth of spectroscopic methods for data collection, suitable for multiple reaction types. We have also demonstrated the use of orthogonal projection approach MCR-ALS for deconstruction of multi-component spectroscopic data collected in-line under push-out conditions, and validated these methods against off-line ${ }^{1} \mathrm{H}$ NMR data collection with traditional manual analysis. We have shown that an extended period of data collection is readily accessible using a 'reverse' push-out of the flow line upon switching from high to low flow rate.

Overall, the methods presented offer great potential for wider adoption of the push-out method to obtain kinetic data, providing opportunities for accelerated reaction study and process development.

\section{Acknowledgements}

The authors thank the Engineering and Physical Sciences Research Council (EPSRC) (EP/G027986/1), GlaxoSmithKline (GSK), and European Regional Development Fund (ERDF) (AI-Chem Channel and IS:CE-Chem within the InterReg programme) for funding this work. We thank Andy Craven and Helen F. Sneddon from GSK for their interest and gratefully acknowledge use of the BORIS (Bristol Online Reaction Investigation Software) software, a result of collaboration between Bristol Chemometrics Group and the PAT\&C, Strategic Technologies and Chemical Development group at GSK.

\section{Notes and references}

1 B. P. Mason, K. E. Price, J. L. Steinbacher, A. R. Bogdan, D. T. McQuade, Chem. Rev., 2007, 107, 2300-2318. 
2 F. Benito-Lopez, W. Verboom, M. Kakuta, J. G. E. Gardeniers, R. J. M. Egberink, E. R. Oosterbroek, A. van den Berg, D. N. Reinhoudt, Chem. Commun., 2005, 2857-2859.

3 (a) T. M. Floyd, M. A. Schmidt, K. F. Jensen, Ind. Eng. Chem. Res., 2005, 44, 2351-2358; (b) R. Herzig-Marx, K. T. Queeney, R. J. Jackman, M. A. Schmidt, K. F. Jensen, Anal. Chem., 2004, 76, 6476-6483; (c) C. B. Leng, J. Hiltner, H. Pham, J. Kelley, M. Mach, Y. H. Zhang, Y. Liu, Phys Chem Chem Phys 2014, 16, 4350-4360; (d) C. Henry, D. Bolien, B. Ibanescu, S. Bloodworth, D. C. Harrowven, X. L. Zhang, A. Craven, H. F. Sneddon, R. J. Whitby, Eur. J. Org. Chem., 2015, 1491-1499.

4 (a) G. Chaplain, S. J. Haswell, P. D. I. Fletcher, S. M. Kelly, A. Mansfield, Aust. J. Chem., 2013, 66, 208-212; (b) In-line Raman spectroscopic analysis of reactor output under mesoscale continuous flow conditions has also been reported, see: T. A. Hamlin, N. E. Leadbeater, Beilstein J. Org. Chem., 2013, 9, 1843-1852., although kinetic studies were not conducted in this example.

5 H. Song, R. F. Ismagilov, J. Am. Chem. Soc., 2003, 125, 14613-14619.

6 (a) M. D. Christianson, E. H. P. Tan, C. R. Landis, J. Am. Chem. Soc., 2010, 132, 11461-11463; (b) H. Wensink, F. Benito-Lopez, D. C. Hermes, W. Verboom, H. J. G. E. Gardeniers, D. N. Reinhoudt, A. van den Berg, Lab Chip 2005, 5, 280-284; (c) S. T. Xu, W. P. Zhang, X. C. Liu, X. W. Han, X. H. Bao, J. Am. Chem. Soc., 2009, 131, 13722-13727.

7 S. Singh, M. F. de Leon, Z. J. Li, J. Phys. Chem. A, 2013, 117, 10863-10872.

8 (a) J. P. McMullen, K. F. Jensen, Org. Process Res. Dev., 2011, 15, 398-407; (b) B. J. Reizman, K. F. Jensen, Org. Process Res. Dev., 2012, 16, 1770-1782.

9 S. Mozharov, A. Nordon, J. M. Girkin, D. Littlejohn, Lab Chip, 2010, 10, 2101-2107.

10 S. Mozharov, A. Nordon, D. Littlejohn, C. Wiles, P. Watts, P. Dallin, J. M. Girkin, J. Am. Chem. Soc., 2011, 133, 36013608.

11 J. S. Moore, K. F. Jensen, Angew. Chem. Int. Ed., 2014, 53, 470-473.

12 S. W. E. Eisenberg, M. J. Kurth, W. H. Fink, J. Org. Chem., 1995, 60, 3736-3742.

13 (a) R. J. Clemens, J. A. Hyatt, J. Org. Chem., 1985, 50, 24312435; (b) M. Sato, H. Ogasawara, S. Komatsu, T. Kato, Chem. Pharm. Bull. 1984, 32, 3848-3856.

14 R. J. Clemens, J. S. Witzeman, J. Am. Chem. Soc., 1989, 111, 2186-2193.

15 D. M. Birney, X. L. Xu, S. Ham, X. M. Huang, J. Org. Chem., 1997, 62, 7114-7120.

16 M. Sato, H. Ogasawara, K. Kato, M. Sakai, T. Kato, Chem. Pharm. Bull., 1983, 31, 4300-4305.

17 Dispersion leads to the $\tau_{0}$ and $\tau_{1}$ inflection points being difficult to assign exactly. We found the most reliable method was to estimate $\tau_{0}$, then calculate $\tau_{1}$ from the flow rate corrected for thermal expansion of solvent using $\left(\tau_{1}-\tau_{0}\right)=\mathrm{V} /$ $F_{2}(1+\alpha \Delta T)$. Where $V$ is the volume of the reactor and $\alpha=$ the expansion coefficient of solvent. The derived $1^{\text {st }}$ order rate constant showed very little sensitivity to the precise point chosen for $\tau_{0}$ within reasonable uncertainty ( \pm 5 seconds in $\tau_{0}$ led to a maximum of $\pm 5 \%$ in the corresponding rate constant).

18 (a) A. R. Carvalho, R. G. Brereton, T. J. Thurston, R. E. A. Escott, Chemom. Intell. Lab. Syst., 2004, 71, 47-60; (b) T. J. Thurston, R. G. Brereton, Analyst, 2002, 127, 659-668; (c) R. G. Brereton, Chemometrics: Data Analysis for the Laboratory and Chemical Plant, Wiley, Chichester, 2003.

19 (a) R. Tauler, B. Kowalski, S. Fleming, Anal. Chem., 1993, 65, 2040-2047; For recent examples of multivariate curve resolution applied to quantitative analysis of multicomponent UV spectra in reaction study see: (b) M. De Luca, S. Mas, G.
Ioele, F. Oliverio, G. Ragno, R. Tauler, Int. J. Pharm. (Amsterdam, Neth.), 2010, 386, 99-107; (c) B. Hemmateenejad, K. Javidnia, M. Saeidi-Boroujeni, J. Pharm. Biomed. Anal., 2008, 47, 625-630; (d) X. T. Zheng, X. C. Gong, Q. Li, H. B. Qu, Ind. Eng. Chem. Res., 2012, 51, 3238 3245.

20 (a) S. Gourvenec, D. L. Massart, Anal. Bioanal. Chem., 2004, 380, 373-375; (b) F. C. Sanchez, J. Toft, B. vandenBogaert, D. L. Massart, Anal. Chem. 1996, 68, 79-85.

21 G. I. Taylor, Proc. R. Soc. Lond. A, 1953, 186-203.

22 (a) D. M. Ruthven, Chem. Eng. Sci., 1971, 26, 1113-1121; (b) J. H. M. Vandenberg, R. S. Deelder, Chem. Eng. Sci., 1979, 34, 1345-1347.

23 Vandenberg and Deelder (ref. 22b) observed that Dean circulation starts when $\mathrm{DnSc}^{1 / 2}>12$ (where $\mathrm{Dn}$ is the Dean number and $\mathrm{Sc}$ is the Schmidt number) and follows the empirical relationship $\kappa=-5.6\left(\mathrm{DnSc}^{1 / 2}\right)^{-0.68}$ where $\kappa$ is the ratio of observed dispersion coefficient to that predicted for a linear system, though their maximum value of $\mathrm{DnSc}^{1 / 2}$ was 500. In our system $\mathrm{DnSc}^{1 / 2}$ is $13.8,138$ and 1380 for flow rates of $0.1,1$ and $10 \mathrm{~mL} \mathrm{~min}^{-1}$ respectively, in acetonitrile at $30{ }^{\circ} \mathrm{C}$. At $0.1 \mathrm{~mL} \mathrm{~min}^{-1}$ dispersion is close to that predicted for a linear capillary, and at $1 \mathrm{~mL} \min ^{-1}$ it is in good agreement with the prediction of Vanderberg and Deelder. The dispersion at $10 \mathrm{~mL} \mathrm{~min}^{-1}$ is considerably less than predicted by the empirical equation but is also well outside the range for which it was validated.

24 S. N. Huckin, L. Weiler, J. Am. Chem. Soc., 1974, 96, 10821087.

25 (a) A. Boulangé, P. A. Peixoto, X. Franck, Chem. Eur. J., 2011, 17, 10241-10245; (b) N. Haddad, I. Rukhman, Z. Abramovich, J. Org. Chem., 1997, 62, 7629-7636; (c) K. E. Henegar, J. D. Winkler, Tetrahedron Lett., 1987, 28, 10511054; (d) P. A. Peixoto, A. Boulangé, S. Leleu, X. Franck, Eur. J. Org. Chem., 2013, 3316-3327; (e) A. Boulangé, J. Parraga, A. Galán, N. Cabedo, S. Leleu, M. J. Sanz, D. Cortes, X. Franck, Bioorg. Med. Chem., 2015, 23, 3618-3628; (f) P. A. Piexoto, A. Boulangé, M. Ball, B. Naudin, T. Alle, P. Cosette, P. Karuso, X. Franck, J. Am. Chem. Soc., 2014, 136, 15248-15256 